

\title{
Research
}

\section{Out-of-hospital cardiac arrest management by first responders: Retrospective review of a fire fighter first responder program}

\author{
Christian Winship BEH(Pmed)(Hons) ${ }^{1}$, Malcolm Boyle PhD¹, Brett Williams PhD¹
}

\author{
Affiliation: \\ ${ }^{1}$ Monash University, Victoria
}

\begin{abstract}
Introduction

Over 9500 people die annually in Australia from sudden cardiac arrest. Strong evidence suggests early, high quality cardiopulmonary resuscitation (CPR) and early counter shock are paramount for improving survival from cardiac arrest. It has also been shown that first responder programs have been able to reduce response times and increase survival rates for out-of-hospital cardiac arrest. The objective of this study was to examine data from the first 7 years of an Australian out-of-hospital cardiac arrest first responder program where fire fighters provided basic life support.
\end{abstract}

\section{Methods}

This study was a retrospective cohort study of all cardiac arrests attended by the Metropolitan Fire and Emergency Services Board (MFESB) as part of the Emergency Medical Response program over a 7-year period in Melbourne, Victoria.

\section{Results}

The MFESB attended 4450 cardiac arrests. The majority of patients presented in asystole 669 (63.7\%) with just 243 (23.1\%) presenting in a shockable rhythm. The majority of patients in cardiac arrest were males $(64.2 \%)$ and the mean age of the patients was 67.5 years. The MFESB median response time during the study period was 5.7 minutes (IQR 2.25 minutes), range $0.15-31.7$ minutes, which remained stable over the 7 years. Patients spent a median time of 4.6 minutes ( 0.02 seconds to 36.5 minutes) in the care of fire fighters prior to the arrival of emergency medical services. The rhythm on handover to paramedics was asystole in 787 $(75.1 \%)$ cases with no shockable rhythms. One in three $(31.3 \%)$ patients received bystander CPR, with a significant rise in the rate of bystander CPR occurring over the past 2 years.

\section{Conclusion}

This study demonstrated acceptable response times to cardiac arrests and a low bystander CPR rate prior to arrival of the MFESB. The incidence of a shockable rhythm on arrival of the MFESB was low with the main rhythm being asystole. The main rhythm on handover to paramedics was asystole with non-shockable rhythms. Further research is required to determine the effect on patient outcomes.

\section{Keywords}

First responder; fire fighter; heart arrest; cardiopulmonary resuscitation; prehospital 


\section{Introduction}

In 2007, approximately 9500 people died of a cardiac arrest in Australia (1) accounting for approximately $7 \%$ of all deaths. Data from the Metropolitan Ambulance Service in Melbourne, Victoria (MAS, now known as Ambulance Victoria [AV]) between January 2002 and December 2003 showed that approximately 8256 cardiac arrests were attended in the metropolitan Melbourne area (2). There is strong evidence to suggest that early cardiopulmonary resuscitation (CPR) by trained healthcare professionals or bystanders and early counter shock can dramatically increase the likelihood of obtaining return of spontaneous circulation (ROSC) and survival from out-of-hospital cardiac arrest (OHCA) (3-7). This resulted in the concept of the 'chain of survival' which was endorsed by the American Heart Association (3). The 'chain of survival' is a sequence of four key events that increases survival from OHCA: early recognition and early access to emergency medical services (EMS), early CPR, early counter shock, and then, early advanced cardiac life support (ACLS) (3).

Early access to EMS is a critical factor in surviving an OHCA $(5,7)$. Early, high quality CPR by either trained healthcare professionals or bystanders, is essential to supplying both the brain and the heart with oxygenated blood and maintaining viability of these important organs (3,6-13). Early high quality CPR also assists in slowing the progression of cardiac rhythm from ventricular fibrillation (VF), which is reversible with defibrillation, to asystole where there is a dramatic drop in survival rates, as well as improving the likelihood of successful cardioversion from VF $(4,7,10,13,14)$. Early counter shock can result in termination of potentially fatal cardiac rhythms and return the heart to normal rhythm (15) resulting in improved organ perfusion $(3,13,15)$. In cardiac catheterisation laboratories there have been reports of successful cardioversion VF cardiac arrest rates as high as 100\% (5), highlighting that early counter shock is key to increasing the likelihood of survival from cardiac arrest $(3,7,13,16-28)$.

As EMS response times increase due to factors such as lack of resources and increasing workload, it is becoming increasingly difficult for these potential lifesaving interventions to be implemented in a timely fashion $(13,29,30)$. This has led to the development of first responder programs where non-healthcare professionals have been trained to perform basic life support and utilise an automatic external defibrillator (AED) in an effort to address increasing EMS response times (31).

The use of first responders has allowed patients who have suffered an OHCA to receive basic life support and early counter shock before EMS services have arrived in a range of urban and rural settings, and therefore potentially improving patient outcomes $(18,20-23,29-46)$. First responders programs come in many forms, including fire fighter first responder, police first responders and in other forms such as airline employees.

\section{Fire fighter first responders}

The use of fire fighter first responder programs has been a part of the EMS in the United States for decades (42), and these programs both in the US and abroad have shown decreased response times and decreased time to counter shock $(33,36,42,43,46,47)$. Several studies demonstrated that fire fighter first responders were able to increase the number of patients surviving $\mathrm{OHCA}(42,43,46,47)$. Hollenberg et al showed a decrease in survival rates from $\mathrm{OHCA}$ after the conclusion of their fire fighter first responder program pilot in Sweden (43).

\section{Emergency medical response programs in Australia}

While the concept of fire fighter first responders is not a new one, the MFESB Emergency Medical Response (EMR) program was the first time that a fire fighter first responder program had been established in Australia. The EMR was activated when there was a suspected cardiac arrest or impending cardiac arrest (such as a patient with ineffective breathing and altered conscious state) within the area covered by the MFESB. The initial reporting on the limited 12-month pilot period of this EMR program by Smith et al, demonstrated survival rates internationally comparable but there was no statistically significant difference between the EMS and MFESB survival outcomes. As a result of the positive outcomes of the study by Smith et al, the EMR program was expanded to encompass the entire MFESB coverage area $(30,47)$. Another study was conducted by Boyle et al (31) of the first 7 years of the entire MFESB EMR program where all cases attended were included and examined, demonstrating that the MFESB had a rapid response time to all incidents that they attended during the study period.

There have been several other EMR programs both in Melbourne and throughout Australia. An example of this is Hatzolah, where volunteers from Melbourne's Jewish community provide a first responder service to the Jewish communities in Melbourne, in tandem with AV (44). Hatzolah has only seen a small number of cardiac arrests (34) during that period and the impact of this first responder group on patient outcomes has never been studied (44). Another example is St John Ambulance Australia, which provides first responders for major events. In an examination of cardiac arrests attended by this organisation at a major sporting facility and the Shrine of Remembrance, there was a remarkable $71 \%(n=20$, with $86 \%$ of 28 cardiac arrest patients being transported to hospital alive) survival rate for patients suffering from a cardiac arrest (22). Finally, a first responder program established by the airline, Qantas, showed that there was a role for first responders on aircraft in management of cardiac arrests, with a long term survival rate of $26 \%(21)$.

The objective of this study was to examine data from the first 7 years of an Australian out-of-hospital cardiac arrest first responder program where fire fighters provided basic life support. 


\section{Methods}

\section{Study design}

This study was a retrospective cohort study of all cardiac arrests attended by MFESB over a 7-year period (1 March 2001 to 28 February 2008).

\section{Definition}

A cardiac arrest was defined as patient that presented unconscious with no signs of life such as a pulse or respirations.

\section{Study population}

During the study period the MFESB serviced an area of approximately $1100 \mathrm{~km}^{2}$ with an approximate population of 2 million people. Within this service area, the MFESB has 51 stations with approximately 1400 fire fighters trained to a first responder level. Each fire fighter undertakes an 8-day training course (which is now part of fire fighter basic training) with a 1-day refresher training every 3 years. Fire fighters were trained to perform CPR, in utilising an AED, advanced first aid and the administration of oxygen through a range of means including bag-valve-mask ventilation. There is also regular skills maintenance and regular follow up after incidents by a designated paramedic from AV. Any patient who was found to be in cardiac arrest on the arrival of MFESB was eligible for inclusion in the analysis.

\section{Study process}

The MFESB have three EMR data files that contained relevant data to this study; these included the cardiac arrest data file, the callout data file and the patient care record data file. All files were provided in a Microsoft Excel $($ file format. An electrocardiogram file obtained from each AED after the completion of a cardiac arrest was also provided for review. These data files contain relevant times during the cardiac arrest, cardiac rhythm and other data that is pertinent to analysis of the cardiac arrest. The data were 'cleaned' to ensure that there were no duplicate incidents, and that any outliers were the result of natural variation, and not that of inaccurate data entry.

\section{Data analysis}

The data was analysed using SPSS (Statistical Package for the Social Sciences Version 19.0, SPSS Inc., Chicago, Illinois, USA). Descriptive statistics, including means and medians, were used to summarise the demographic and specific outcome measure data.

\section{Ethics}

Ethics approval for the study was obtained through the Monash University Standing Committee on Ethics in Research Involving Humans.

\section{Results}

During the study period, the MFESB attended 8227 incidents as part of the EMR program; of this 4450 patients were in cardiac arrest (Table 1). Incidences of cardiac arrest peaked between the hours of $07: 00$ and 10:00 hours and then again between 16:00 and 18:00 hours. Of the 4450 cardiac arrests attended, $64.2 \%$ were male and $32.2 \%$ were female. There were 161 $(3.6 \%)$ case sheets without gender information. The mean age of the patients was 67.5 years (range 1 month to 101 years). The overall mean response time for the 7 years of the EMR program was 6.31 minutes (range $0.15-31.67$ minutes). Table 1 shows mean response times as well as the range of response time for each of the 7 years of the EMR program.

In $1797(40.4 \%)$ cases, fire fighters provided initial care prior the arrival of paramedics; in 1261 (28.4\%) cases fire fighters provided assistance to paramedics already on scene (Table 2). The mean time that a patient was in the care of fire fighters prior to the arrival of EMS was 4.6 minutes (range $0.02-36.5$ minutes).

Mean time from the ' 000 ' emergency call number was received to defibrillation was 5.9 minutes (from 219 instances where fire fighters performed defibrillation), range $0.38-10.5$ minutes. The mean time from arrival on scene to defibrillation was 2.1 minutes (range 0.1-6.5 minutes). The most common initial rhythm when the AED was applied was asystole, with 669 $(63.7 \%)$, followed by VF (fine or coarse) with $243(23.1 \%)$, of which 219 received defibrillation before the arrival of paramedics. The remaining 24 patients who were in VF did not receive defibrillation, as the AED was unable to determine that the presenting rhythm was VF (Table 3). The majority of rhythms after the first shock from the AED were asystole with 119 patients $(54.3 \%)$, with 63 patients $(28.8 \%)$ remaining in VF (either fine or coarse). The most common rhythm that was handed over to paramedics by fire fighters was asystole for 787 patients $(75.1 \%)$ followed by VF (either fine or coarse) with 79 patients $(6.5 \%)$. See Table 3 . For the patients who did receive defibrillation, the vast majority only received a single shock in 131 instances (59.3\%) or two defibrillations in 48 instances $(21.7 \%)$, with the range of shocks being from 1 to 30 . Fire fighters only performed single defibrillations during each cycle of CPR, no 'stacked' defibrillations were utilised.

In total, 1392 patients in cardiac arrest had CPR in progress on the arrival of MFESB crews, representing $31.3 \%$ of patients. Also, our results showed that there was a sharp increase in bystander CPR rates in the sixth and seventh year of the program as shown in Table 1. 


\section{Discussion}

The results show that the MFESB EMR program was able to achieve a rapid response time in metropolitan Melbourne, with fire fighters providing care prior to the arrival of EMS in a significant number of patients, and that the vast majority of patients that were treated for OHCA presented in asystole.

\section{Response times}

It is well documented that a response time by either EMS or by first responders is paramount in improving survival and favourable neurological outcome for patients in OHCA, particularly those suffering from VF arrest (17,19-22,29-46). Our study was able to demonstrate a stable mean, 50th and 90th percentile response times, over the course of the 7 years where data were obtained, compared to the EMS service in the same area which had an increasing response time over the same period. During 2001-2002, the AV 50th percentile response time was 8 minutes, which increased to 9.5 minutes by 2007-2008 $(48,49)$. While the AV 90th percentile response time increased from 14 minutes in 2001-2002 to 16.5 minutes in 2007-2008 $(48,49)$. This increase in response times over this period is also substantiated by scientific literature $(2,50-52)$. However, it has been shown in several studies that EMS systems that already have a rapid response time to $\mathrm{OHCA}$, and that implementation of a first responder program leads to minimal, if any, gains in terms of patient outcomes (42).

The Larsen et al study created a multiple linear regression model that can be used to predict the likelihood of survival from VF OHCA (53). This was developed by thorough review of $1667 \mathrm{OHCA}$ patients who presented in VF and had a history of cardiovascular disease. A survival rate of $67 \%$ if the patient received all four links of the chain of survival at the time of arrest; then: $-2.3 \%$ per minute to $\mathrm{CPR}-1.1 \%$ per minute to defibrillation $-2.1 \%$ per minute to ACLS. Effectively survival declines $5.5 \%$ per minute until intervention (53).

The AV 90th percentile response times for urgent cases in 2007-2008 was 16.5 minutes (48). If no bystander CPR was performed in this period, the survival rate would be zero. If $\mathrm{CPR}$ was performed prior to the arrival of $\mathrm{AV}$, then approximate survival rate would be $14.2 \%$. Compared to the MFESB EMR 90th percentile response time of 8.69 minutes, the approximate survival rate if no CPR is performed prior to the arrival of fire fighters is $19.2 \%$, and if CPR is performed prior to the arrival of fire fighters then the approximate survival rate is $39.2 \%$. This is just an approximation for patients that were in VF on arrival of EMS and had a history of cardiovascular disease, and considering that only $23 \%$ of 1050 patients that had an AED applied to them by fire fighters presented in VF, overall survival rates are dismal.

\section{Presenting rhythm}

The most common presenting rhythm, when the AED was applied by fire fighters during this study period was asystole, with $669(63.7 \%$ of all OHCA patients that had an AED applied to them by fire fighters) despite the rapid response time of MFESB and bystander CPR in $31 \%$ of OHCA cases. The significance of the majority of patients presenting in asystole is that from the current data we have, there is a significantly reduced likelihood that ROSC will be achieved, or if ROSC is achieved there is a minimal chance of a reasonable neurological outcome for the patient $(50,54-56)$. The second most common presenting rhythm on application of the AED was VF (fine or coarse VF) with 243 (23.1\%), of which 219 received at least one counter shock prior to the arrival of paramedics (Table 3 ). The majority of patients $(119,54.3 \%)$ that received a counter shock reverted into asystole post counter shock, which may be due to the fact that the counter shock is being delivered to a hypoxic myocardium (57-59). This further highlights the debate on whether or not CPR should be performed before the initial counter shock is delivered, increasing the likelihood of successful reversion and possibly preventing the patient progressing into asystole (60-62). Only 63 (28.8\%) of the patients remained in VF (either coarse or fine), post counter shock, with the remainder reverting to other rhythms (Table 3).

\section{Bystander CPR}

Only $31 \%$ of patients (or approximately 1350 patients) received any form of bystander CPR prior to the arrival of fire fighters, which is comparable with reported rates of bystander CPR, which range from $12.1 \%$ (42) to $51.5 \%$ (39). The majority of reporting was in the range of $30-40 \%$, however, there was a large amount of variance in the numbers of patients enrolled in each study which reduces the accuracy of these percentages $(18,20,23,41,43-45)$. As highlighted previously, if bystander CPR is not performed in the initial period of OHCA then the probability of survival drastically declines with each minute, as shown by the multiple linear regression performed by Larson et al (53). As shown in Table 1, bystander CPR rates were $25-28 \%$ for the first 5 years of the program, with a sharp increase in bystander CPR rates up to $44 \%$ in the seventh year. We believe that this increase in bystander CPR rates was due to a change in CPR instructions by EMS dispatchers, as has been described by Bray et al (63).

\section{Limitations of this study}

This study is potentially limited by the fact that we were unable to link the data we obtained from MFESB EMR program and the Victorian Cardiac Arrest Registry. This limited our ability to determine if the EMR program had any significant survival or neurological benefits for patients. Our study was also limited by the fact that the data was obtained from a third party rather than the research team collecting it, resulting in the possibility of missing data.

\section{Future recommendations}

In the future we would like to link the cardiac arrest outcome data to the results we have obtained in order to get a true determination of the effect of this program on patient survival and neurological outcome. Our study has also highlighted that 
there needs to be an increased drive to educate the public on the importance of providing CPR to a person who has suffered a cardiac arrest. Despite bystander CPR rates being comparative to international rates, this can still be improved.

\section{Conclusion}

Our study into the management of OHCA by fire fighter first responders showed a significant reduction in response times when compared to the ambulance service that provided EMS to the same area. It also revealed that the vast majority of patients in cardiac arrest on arrival of EMR presented in asystole, with approximately $23 \%$ presenting in VF, and that $31 \%$ of patients in cardiac arrest received bystander CPR before the arrival of fire fighter first responders in metropolitan Melbourne, an area that needs to be targeted in future public education programs. In the future we hope to be able to link our findings from the MFESB EMR program to patient outcome data to be able to measure the true success of the program.

\begin{tabular}{|c|c|c|c|c|c|r|}
\hline & \multicolumn{2}{|l|}{$\begin{array}{l}\text { Number of cardiac arrests per } \\
\text { year }\end{array}$} & \multicolumn{2}{l|}{$\begin{array}{c}\text { Breakdown of response times } \\
\text { over the EMR program }\end{array}$} & \multicolumn{2}{l|}{ Bystander CPR rates by year } \\
\hline Year & Frequency & Percentage & Mean & Range & $\begin{array}{c}\text { Number of } \\
\text { cardiac } \\
\text { arrests }\end{array}$ & $\begin{array}{c}\text { Bystander CPR } \\
\text { rates }(\%)\end{array}$ \\
\hline 1 & 638 & $14.3 \%$ & 6.14 & $1.30-26.92$ & 638 & $169(26.5 \%)$ \\
\hline 2 & 609 & $13.7 \%$ & 6.45 & $2.09-29.31$ & 609 & $158(25.9 \%)$ \\
\hline 3 & 705 & $15.8 \%$ & 6.07 & $2.43-30.74$ & 705 & $178(25.3 \%)$ \\
\hline 4 & 597 & $13.4 \%$ & 6.42 & $0.15-27.30$ & 597 & $171(28.6 \%)$ \\
\hline 5 & 526 & $11.8 \%$ & 6.49 & $2.07-31.67$ & 626 & $151(28.7 \%)$ \\
\hline 6 & 610 & $13.7 \%$ & 6.55 & $1.17-17.93$ & 610 & $228(37.4 \%)$ \\
\hline 7 & 765 & $17.2 \%$ & 6.14 & $1.00-23.37$ & 765 & $337(44.1 \%)$ \\
\hline Total & 4450 & $100 \%$ & 6.31 & $0.15-31.67$ & 4450 & $1392(31.3 \%)$ \\
\hline
\end{tabular}

Table 1. Breakdown of cardiac arrests over the EMR program

\begin{tabular}{|l|r|}
\hline Action & \multicolumn{1}{|c|}{$\mathrm{n}(\%)$} \\
\hline Provided initial care & $1797(46.1 \%)$ \\
\hline Assisted Paramedics with care & $1261(32.2 \%)$ \\
\hline Investigated/observed & $838(21.5 \%)$ \\
\hline Cancelled/downgraded & $4(0.1 \%)$ \\
\hline
\end{tabular}

Table 2. Breakdown of care provided by fire fighters

\begin{tabular}{|l|c|c|c|}
\hline Rhythm & $\begin{array}{c}\text { Initial rhythm } \\
\text { Frequency }\end{array}$ & $\begin{array}{c}\text { Rhythm after first } \\
\text { counter shock (n=219) }\end{array}$ & $\begin{array}{c}\text { Final rhythm } \\
\text { Frequency }\end{array}$ \\
\hline Coarse VF & $81(7.7 \%)$ & $16(7.3 \%)$ & $16(1.5 \%)$ \\
\hline Fine VF & $162(15.4 \%)$ & $47(21.5 \%)$ & $63(6.0 \%)$ \\
\hline Asystole & $669(63.7 \%)$ & $119(54.3 \%)$ & $787(75.1 \%)$ \\
\hline Pulseless Electrical activity & $138(13.2 \%)$ & $37(16.9 \%)$ & $182(17.4 \%)$ \\
\hline Total & $1050(100 \%)$ & $219(100 \%)$ & $1048(100 \%)$ \\
\hline
\end{tabular}

Table 3. Initial and final rhythm breakdown 


\section{References}

1. Australia's Health 2010. Available at: www.aihw.gov.au/ publications/aus/ah10/ah10.pdf [Accessed July 2010].

2. Jennings P, Cameron P, Walker T, Bernard S, Smith K. Out-ofhospital cardiac arrest in Victoria: rural and urban outcomes. Med J Aust 2006;185(3):135-9.

3. Cummins RO, Ornato JP, Thies WH, Pepe PE. Improving survival from sudden cardiac arrest: the "chain of survival" concept. A statement for health professionals from the Advanced Cardiac Life Support Subcommittee and the Emergency Cardiac Care Committee, American Heart Association. Circulation 1991;83(5):1832-47.

4. Hollenberg J, Herlitz J, Lindqvist J, et al. Improved survival after out-of-hospital cardiac arrest is associated with an increase in proportion of emergency crew-witnessed cases and bystander cardiopulmonary resuscitation. ibid. 2008;118(4):389-96.

5. Rea TD, Eisenberg MS, Culley LL, Becker L. Dispatcher-assisted cardiopulmonary resuscitation and survival in cardiac arrest. ibid. 2001;104(21):2513-6.

6. Lund I, Skulberg A. Cardiopulmonary resuscitation by lay people. Lancet 1976;308(7988):702-4.

7. Roth R, Stewart RD, Rogers K, Cannon GM. Out-of-hospital cardiac arrest: factors associated with survival. Ann Emerg Med 1984;13(4):237-43.

8. Stueven H, Troiano P, Thompson B, et al. Bystander/first responder CPR: ten years experience in a paramedic system. ibid. 1986;15(6):707-10.

9. Swor RA, Boji B, Cynar M, et al. Bystander vs EMS firstresponder CPR: initial rhythm and outcome in witnessed nonmonitored out-of-hospital cardiac arrest. Acad Emerg Med 1995;2(6):494-8.

10. Guzy PM, Pearce ML, Greenfield S. The survival benefit of bystander cardiopulmonary resuscitation in a paramedic served metropolitan area. Am J Public Health 1983;73(7):766-9.

11. Waalewijn RA, de Vos R, Tijssen JG, Koster RW. Survival models for out-of-hospital cardiopulmonary resuscitation from the perspectives of the bystander, the first responder, and the paramedic. Resuscitation 2001;51(2):113-22.

12. Shah S, Garcia M, Rea TD. Increasing first responder CPR during resuscitation of out-of-hospital cardiac arrest using automated external defibrillators. ibid. 2006;71(1):29-33.

13. Herlitz J, Ekstrom L, Wennerblom B, Axelsson A, Bang A, Holmberg S. Survival in patients found to have ventricular fibrillation after cardiac arrest witnessed outside hospital. Eur Heart J 1994;15:1628-33.

14. Box MS, Watson JN, Addison PS, Clegg GR, Robertson CE. Shock outcome prediction before and after CPR: a comparative study of manual and automated active compressiondecompression CPR. Resuscitation 2008;78(3):265-74.

15. Australian Resuscitation Council, New Zealand Resuscitation Council. Electrical Therapy for Adult Advanced Life Support. ARC and NZRC Guideline 2010. Emerg Med Australas 1;23(3):27781.

16. Baker PW, Conway J, Cotton C, et al. Defibrillation or cardiopulmonary resuscitation first for patients with outof-hospital cardiac arrests found by paramedics to be in ventricular fibrillation? A randomised control trial. Resuscitation 2008;79(3):424-31.

17. Eisenberg MS, Copass MK, Hallstrom AP, et al. Treatment of Out-of-Hospital Cardiac Arrests with Rapid Defibrillation by Emergency Medical Technicians. N Engl J Med 1980;302(25):1379-83.

18. Hess EP, White RD. Recurrent ventricular fibrillation in outof-hospital cardiac arrest after defibrillation by police and firefighters: implications for automated external defibrillator users. Crit Care Med. 2004;32(9 Suppl):S436-9.

19. Mancini ME. First-responder defibrillation. Nursing Spectrum 1997;9A(15):4.

20. Mosesso VN, Jr., Davis EA, Auble TE, Paris PM, Yealy DM. Use of automated external defibrillators by police officers for treatment of out-of-hospital cardiac arrest. Ann Emerg Med 1998;32:200-7.

21. O'Rourke M, Donaldson E, Geddes J. An airline cardiac arrest program. Circulation 1997;96(9):2849-53.

22. Wassertheil J, Keane G, Fisher N, Leditschke J. Cardiac arrest outcomes at the Melbourne Cricket Ground and Shrine of Remembrance using a tiered response strategy - A forerunner to public access defibrillation. Resuscitation 2000;44(2):97-104.

23. White RD, Asplin BR, Bugliosi TF, Hankins DG. High discharge survival rate after out-of-hospital ventricular fibrillation with rapid defibrillisation by police and paramedics. Ann Emerg Med 1996;28:480-5.

24. Scott IA, Fitzgerald GJ. Early defibrillation in out-of-hospital sudden cardiac death: an Australian experience. Arch Emerg Med 1992;10:1-7.

25. Weaver WD, Copass MK, Hill DL, Fahrenbruch C, Hallstrom AP, Cobb LA. Cardiac arrest treated with a new automatic external defibrillator by out-of-hospital first responders. Am J Cardiol 1986;57(13):1017-21.

26. Weaver WD, Hill DL, Fahrenbruch C, et al. Use of Automatic External Defibrillation in the Management of Out-of-Hospital Cardiac Arrest. N Engl J Med 1988;319(11):661-6.

27. Stults KR, Brown DD, Schug VL, Bean JA. Prehospital defibrillation performed by emergency medical technicians in rural communities. N Engl J Med 1984;310(4):219-23.

28. Valenzuela TD, Roe DJ, Cretin S, Spaite DW, Larsen MP. Estimating effectiveness of cardiac arrest interventions: a logistic regression survival model. Circulation. 1997;96(10):3308-13.

29. Smith KL, McNeil JJ, Emergency Medical Response Steering Committee. Cardiac arrests treated by ambulance paramedics and fire fighters. Med J Aust. 2002;177(6):305-9.

30. Smith KL, Peeters A, McNeil JJ. Results from the first 12 months of a fire first-responder program in Australia. Resuscitation 2001;49(2):143-50.

31. Boyle MJ, Williams B, Bibby C, Morton A, Huggins C. The first 7 years of the metropolitan fire brigade emergency responder program - An overview of incidents attended. Open Access Emerg Med 2010;2:77-82.

32. Craig AM, Verbeek PR, Schwartz B. Evidence-based optimization of urban firefighter first response to emergency medical services 9-1-1 incidents. Prehosp Emerg Care 2010;14(1):109-17.

33. Hoyer CB, Christensen EF. Fire fighters as basic life support responders: a study of successful implementation. Scand J Trauma Resusc Emerg Med 2009;17:16. 
34. Kellermann AL, Hackman BB, Dobyns P, Frazier C, Nail L. Engineering excellence: options to enhance firefighter compliance with standing orders for first-responder defibrillation. Ann Emerg Med 1993;22(8):1269-75.

35. Lerner EB, Billittier Iv AJ, Newman MM, Groh WJ. Automated external defibrillator (AED) utilization rates and reasons fire and police first responders did not apply AEDs. Prehosp Emerg Care 2002;6(4):378-82.

36. Shuster M, Keller JL. Effect of fire department first-responder automated defibrillation. Ann Emerg Med 1993;22(4):721-7.

37. Smith K, Rich D, Pinol JP, Hankin J, McNeil J. Acceptance of a medical first-responder role by fire fighters. Resuscitation 2001;51(1):33-8.

38. Groh WJ, Newman MM, Beal PE, Fineberg NS, Zipes DP. Limited response to cardiac arrest by police equipped with automated external defibrillators: lack of survival benefit in suburban and rural Indiana - The Police as Responder Automated Defibrillation Evaluation (PARADE). Acad Emerg Med 2001;8(4):324-30.

39. Mosesso VN, Jr., Newman MM, Ornato JP, et al. Law enforcement agency defibrillation (LEA-D): proceedings of the National Center for Early Defibrillation Police AED issues forum. Prehosp Emerg Care 2002;6(3):273-82.

40. Myerburg RJ, Fenster J, Velez M, et al. Impact of communitywide police car deployment of automated external defibrillators on survival from out-of-hospital cardiac arrest. Circulation 2002;106:1058-64.

41. Callaham M, Braun O, Valentine W, Clark DM, Zegans C. Prehospital cardiac arrest treated by urban first-responders: profile of patient response and prediction of outcome by ventricular fibrillation waveform. Ann Emerg Med 1993;22(11):1664-77.

42. Kellermann AL, Hackman BB, Somes G, Kreth TK, Nail L, Dobyns $P$. Impact of first-responder defibrillation in an urban emergency medical services system. JAMA 1993;270(14):170813.

43. Hollenberg J, Riva G, Bohm K, Nordberg P, Larsen R, Herlitz J, et al. Dual dispatch early defibrillation in out-of-hospital cardiac arrest: the SALSA-pilot. Eur Heart J 2009;30(14):1781-9.

44. Chan T, Braitberg G, Elbaum D, Taylor D. Hatzolah emergency medical responder service: to save a life. Med J Aust 2007;186(12):639-42.

45. Sedgwick ML, Dalziel K, Watson J, Carrington DJ, Cobbe SM. Performance of an established system of first responder outof-hospital defibrillation. The results of the second year of the Heartstart Scotland Project in the 'Utstein Style'. Resuscitation 1993;26(1):75-88.

46. van Alem AP, Vrenken RH, de Vos R, Tijssen JGP, Koster RW. Use of automated external defibrillator by first responders in out of hospital cardiac arrest: prospective controlled trial. BMJ 2003;327(7427):1312.

47. Smith KL, McNeil JJ, Emergency Medical Response Steering Committee. Cardiac arrests treated by ambulance paramedics and fire fighters. Med J Aust 2002;177(6):305-9.
48. Metropolitan Ambulance Service. Metropolitan Ambulance Service Annual Report. Doncaster: Metropolitan Ambulance Service, 2008.

49. Metropolitan Ambulance Service. Metropolitan Ambulance Service 2005-2006 Annual Report. Doncaster: Metropolitan Ambulance Service, 2006.

50. Bernard S. Outcome from prehospital cardiac arrest in Melbourne, Australia. Emerg Med 1998;10:25-9.

51. Jackson P. Prehospital Defibrillation in Geelong. Emerg Med 1993;5:184-7.

52. Jennings $P$, Pasco J. Survival from out-of-hospital cardiac arrest in the Geelong region of Victoria, Australia. Emerg Med (Fremantle) 2001;13(3):319-25.

53. Larsen MP, Eisenberg MS, Cummins RO, Hallstrom AP. Predicting Survival From Out-of-Hospital Cardiac Arrest: A Graphic Model. Ann Emerg Med 1993;22(11):1652-8.

54. Gundersen K, Kvaloy JT, Kramer-Johansen J, Steen PA, Eftestol T. Development of the probability of return of spontaneous circulation in intervals without chest compressions during outof-hospital cardiac arrest: an observational study. BMC Med 2009;7:6.

55. Handel DA, Gallo P, Schmidt M, et al. Prehospital cardiac arrest in a paramedic first-responder system using the Utstein style. Prehosp Emerg Care 2005;9(4):398-404.

56. Heightman AJ. Impact of early care: first responder care often makes the difference. JEMS 2011;36(4):14.

57. Jacobs IG, Finn JC, Oxer HF, Jelinek GA. CPR before defibrillation in out-of-hospital cardiac arrest: A randomized trial. Emerg Med Australas 2005;17(1):39-45.

58. Cobb LA, Fahrenbruch CE, Walsh TR, et al. Influence of cardiopulmonary resuscitation prior to defibrillation in patients with out-of-hospital ventricular fibrillation. J Am Med Assoc 1999;281(13):1182-8.

59. Hayakawa M, Gando S, Okamoto H, Asai Y, Uegaki S, Makise $\mathrm{H}$. Shortening of cardiopulmonary resuscitation time before the defibrillation worsens the outcome in out-of-hospital VF patients. Am J Emerg Med 2009;27(4):470-4.

60. Winship C, Williams B, Boyle M. Cardiopulmonary resuscitation before defibrillation in the out-of-hospital setting: A literature review. Emerg Med J 2012;29(10):826-9.

61. Wik L, Hansen TB, Fylling F, Steen T, Vaagenes P, Auestad BH, et al. Delaying Defibrillation to Give Basic Cardiopulmonary Resuscitation to Patients with Out-of-Hospital Ventricular Fibrillation: A Randomized Trial. J Am Med Assoc 2003;289(11):1389-95.

62. Eftestol T, Wik L, Sunde K, Steen PA. Effects of cardiopulmonary resuscitation on predictors of ventricular fibrillation defibrillation success during out-of-hospital cardiac arrest. Circulation 2004;110(1):10-5.

63. Bray JE, Deasy C, Walsh J, Bacon A, Currell A, Smith K. Changing EMS dispatcher CPR instructions to 400 compressions before mouth-to-mouth improved bystander CPR rates. Resuscitation 2011;82(11):1393-8. 